\title{
Installation of Mechatronics Education Using the MindStorms for Dept. of Mechanical Engineering, O.N.C.T
}

\author{
Tatsushi Tokuyasu \\ Oita National College of Technology \\ Japan
}

\section{Introduction}

In the late 1950s Japanese economy were growing remarkable. In order to sustain this economic growth and foster human resources who can provide advances in technology and science, the government established particular kind of educational institution, National College of Technology, in 1962. The educational system of National College of Technology is positioned between industrial high school and technological university, because the age range of student is from fifteen to twenty. Basically, the first grade students are the graduates of junior high school so that students are not sufficiently grown to understand special subjects and mechanisms of most advanced technologies. There are 55 scholastic institutions throughout Japan at the present day, so that one or two schools have been established in each prefecture. Each school is allowed to construct department and to have own educational curriculum, and most of schools have own advanced course (http://www.kosen-k.go.jp/english/index.html).

Educational programs for early year are mainly composed of general studies such as mathematics, foreign and international languages, social studies, and physical education, and so on. Meanwhile special subjects including graduation research are implemented in higher-grade educational program. The purpose of graduation research is to foster the ability as engineer, and then final-year students engage in researching at their interesting laboratory for one year, in which lots of scientific papers have been published every year.

Mechatronics is one of the major technical studies and consists of wide variety of technologies, such as mechanics, electronics, programming, and robotics, and so on, so that it is difficult to compose an educational program of mechatronics. In fact, many textbooks for mechatronics covering a broad range of specific subject have been published. To select a text book suit for levels of student is also difficult. Then, the author assumed that practical work more effect for mechatronics installation education than classroom lecture using textbooks.

Mind Storms, a set of small plastic and various shaped blocks, motors and several different types of sensors, produced by LEGO Group, has been already known as one of good educational toolkits for mechatronics installation(Komatsu et al., 2000)(Nakashima et al., 
2001)(Inagaki et al., 2001). A variety of of guide books for MindStorms have been published[5]. By using a toolkit of MindStorms, trainers can easily get trainees started on learning the basic factors of manufacturing. In the department of mechanical engineering of Oita National College of Technology, mechatronics education begins from the first grade as a part of practical training program. This chapter introduces a method of mechatronics installation by using Mind Storms have implemented in the department of mechanical engineering of Oita National College of Technology (http://www.oita-ct.ac.jp/).

\title{
2. Orientation
}

The mechatronics installation education presented in this chapter have been implemented as a part of practical training subject from 2006 against the first grade students belonging to department of mechanical engineering. The practical training of the first grade student is composed of the following six courses; lathe turning machine (eighteen hours), drafting (three hours), hand finishing (fifteen hours), mechatronics installation (eighteen hours), assembly of a micro-car (twelve hours), and fishing lure manufacturing (six hours). Because of a number of classmates, forty students take part in the course every year, students are divided into four groups. Each group participates in these courses as shown in Table 1. Total learning time of the practical training is twenty-four, and only six times of the total number is assigned to the mechatronics installation course.

In order to make students comprehensively learn a subject of mechatronics, MindStorms has been adopted as educational tool of this mechatronics installation course. MindStorms is an integrated educational toolkit for mechatronics learning. A toolkit contains variouslyshaped blocks, a RCX controller, a Robolab programming software, and some kinds of sensors. It enables students experimentally learn the factors necessary to make a controllable robot. A lot of installation books of MindStorms have been published(Sato, 2000)(Eto, 1999).

\begin{tabular}{|c|c|c|c|c|c|c|c|c|c|c|c|c|c|}
\hline Group & & \begin{tabular}{|l|l}
3 & 4 \\
\end{tabular} & \begin{tabular}{l|l}
5 & 6 \\
\end{tabular} & 7 & 8 & \begin{tabular}{l|l|l}
9 & 10 & 1 \\
\end{tabular} & & \begin{tabular}{|l|l|l}
13 & 14 & 15 \\
\end{tabular} & \begin{tabular}{|l|l|}
16 & 17 \\
\end{tabular} & & \begin{tabular}{|l|l|}
9 & 20 \\
\end{tabular} & \begin{tabular}{|l|l}
22 & 23 \\
\end{tabular} & \begin{tabular}{|l|l|}
23 & 24 \\
\end{tabular} \\
\hline A & & $\mathrm{L}$ & & $\mathrm{D}$ & & $\mathrm{H}$ & & $\mathrm{N}$ & M & & A & & F \\
\hline B & & A & $\mathrm{F}$ & & & L & & D & $\mathrm{H}$ & \multicolumn{4}{|c|}{$\mathrm{M}$} \\
\hline C & \multicolumn{3}{|c|}{$\mathrm{M}$} & & A & 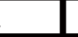 & $F$ & \multicolumn{2}{|c|}{$\mathrm{L}$} & D & & $\mathrm{H}$ & \\
\hline D & $\mathrm{D}$ & \multicolumn{2}{|l|}{$\mathrm{H}$} & \multicolumn{4}{|c|}{$\mathrm{M}$} & A & $\mathrm{F}$ & \multicolumn{4}{|c|}{ L } \\
\hline Month & 4 & 5 & & 6 & & 7 & s & 10 & 11 & & 12 & 1 & 2 \\
\hline Day & 27 & \begin{tabular}{l|l|l|}
11 & 18 & 25 \\
\end{tabular} & \begin{tabular}{|l|l|}
1 & 8 \\
\end{tabular} & 22 & & \begin{tabular}{l|l|l}
6 & 13 & 2 \\
\end{tabular} & 17 & \begin{tabular}{|l|l|l|}
5 & 19 & 26 \\
\end{tabular} & \begin{tabular}{|l|l|}
2 & 9 \\
\end{tabular} & $6 \sqrt{3}$ & \begin{tabular}{|l|l|l|}
0 & 14 & 21 \\
\end{tabular} & & \begin{tabular}{|l|l|}
25 & 1 \\
\end{tabular} \\
\hline
\end{tabular}

\author{
L: Lathe Turning Machine \\ D: Drafting \\ $\mathrm{H}$ : Hand Finishing
}

M: Mechatronics Installation

A: Assembly of A Micro-Car

F: Fishing Lure Manufacturing

Table 1. Time table of practical training though the year

\section{Method}

The subject of practical training has been held for three hours one day a week. Especially, as shown in Table 1, the mechatronics course consists of six lessons. The followings describe the educational contents undertaken in each week. 


\subsection{Installation}

At the first session of this mechatronics course, firstly basic concepts of mechatronics are introduced into the students, for example, a history of robotics, fundamental construction of mechatronics devices, name derivation of mechatronics, and so on. A car wiper drive system, moving from side to side, is one of familiar mechatronics devices even young students, and to think this mechanism is employed as the first problem of this course. Students firstly sketch a mechanism which enable wiper blades to move from side to side under a bonnet of car based on their imagination. Next, they try to shape the sketch by using MindStorms. Fig. 1 shows a piece of work a student made, where four linkage blocks and two gears are used and it achieved to imitate the behaviour of wiper blades. A technical point is to change the direction of motion from rotational movement of gear to linear reciprocating motion in right-and-left of wiper blades.

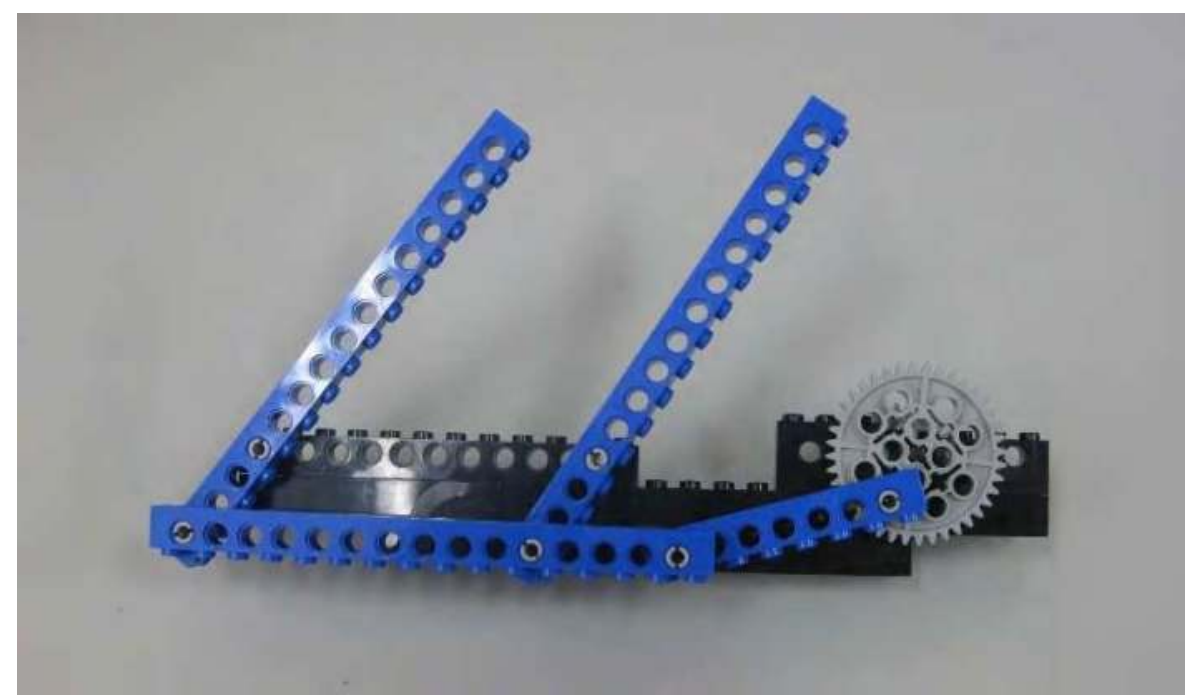

Fig. 1. A car wiper drive mechanism made from MindStorms

\subsection{Duplication of mechanical module}

Several kinds of mechanical modules, such as lever slider, one-way ratchet, spur wheel, geneva drive, eccentric crank, etc, produced by SHINKO engineering research corporation, had been introduced in order to educate dynamics of mechanism. Though a subject of dynamics of mechanism begins in the fourth grade, these modules are suited to installation tools of dynamics of mechanism because students can experimentally observe behaviours of gears, linkages, and other mechanical components. For example, in the case of eccentric crank module as shown in Fig. 2, the rotational motion driven from handle operation is transformed into the translational motion of the work. After observing these mechanical modules, students try to duplicate their favorite mechanical module by using MindStorms. In order to completely build the mechanical module, firstly proper block selection has to be done under considering overall stiffness of module. Some of students wrote a conceptual drawing by using selecting blocks. In the phase of assembling, fitness between other shaped 
blocks due to their different thickness. Most of students selected the eccentric crank and had spent about two hours. Seventy percentage of students could duplicate the function of eccentric crank by using MindStorms.

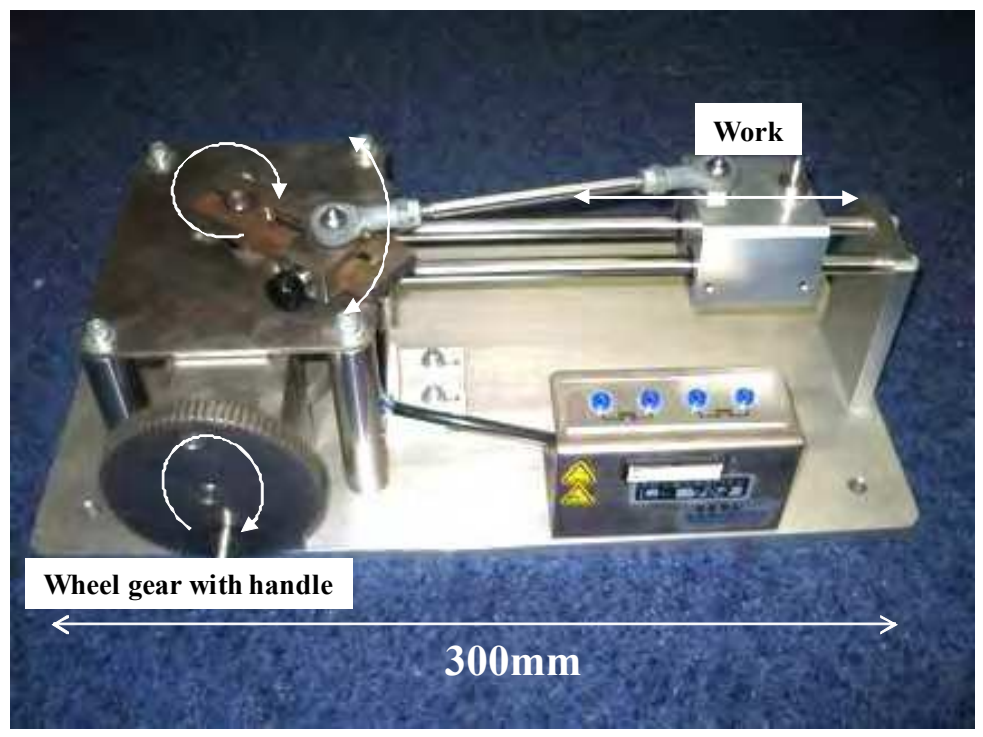

Fig. 2. Mechanical module of eccentric crank

\subsection{Introduction for Sequential Control System}

The third session begins with introduction of sequential control that is used in a variety of devices supporting our dairy comfort life, such as auto vender, laundry machine, and some kind of audio devices, etc. In order to educate sequential control method and mechanisms necessary for running an automated production line, a purchasable miniature model which imitates an automated production line system is adopted. The department had installed an automation education line system few years ago. Fig. 3 shows each work cells of the installed miniature automation line system. This production line makes two simple components to put together on a floating pallet as shown in Fig. 4. The automated sequential tasks of each work cells are followings; the endeffector of the first work cell grasps a male component from the rotary table and puts it on the floating pallet on the belt conveyer. The second work cell has a suction type end effecter which vacuums a female component up and puts it on the male component fixed on the floating pallet, and then two different types of components are completely combined on the pallet. At last, the third cell takes the complete product.

Each of works' movements gathered attention of students. They carefully observed mechanisms of rotary table of the first work and/or movements of each end effecters. A control panel of this automation line system is allocated under the table. Because the control panel administrates all of sensors, actuators, and work processes, each of indication lamps keep lighting-up during the automation system is running. The observation of control panel enables students to learn the roles of controller to manage actuators and sensors. 


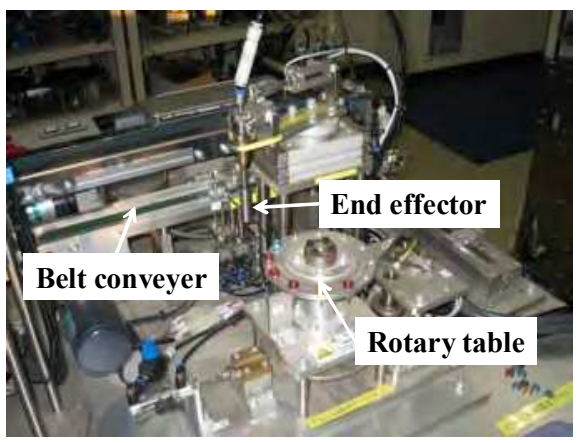

(a) First work cell

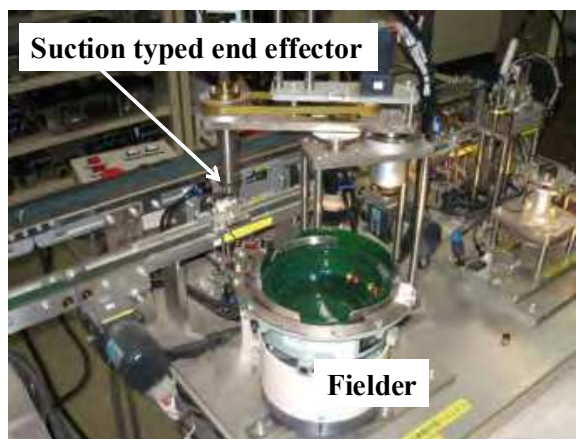

(b) Second work cell

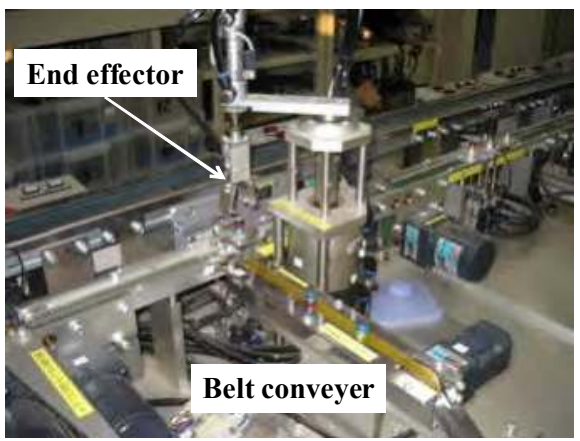

(c) Third work cell

Fig. 3. Main work cells of the miniature automation production line

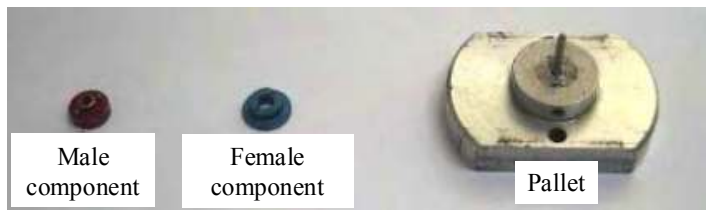

Fig. 4. A pair of components and pallet used in the miniature automated production line 


\subsection{Assemble a multi-legs robot}

In the fourth session a guide book for MindStorms written in Japanese (Sato. 2000) is used as a manual to assemble a mobile robot. This book shows how to assemble several types of robot, such as multi-legs walking robot and wheel type mobile robot and so on. Fig. 5 shows a multi-legs walking robot named Musimusi No.5, which can be built by reference to the study guide. It averagely took about an hour and a half to complete this robot.

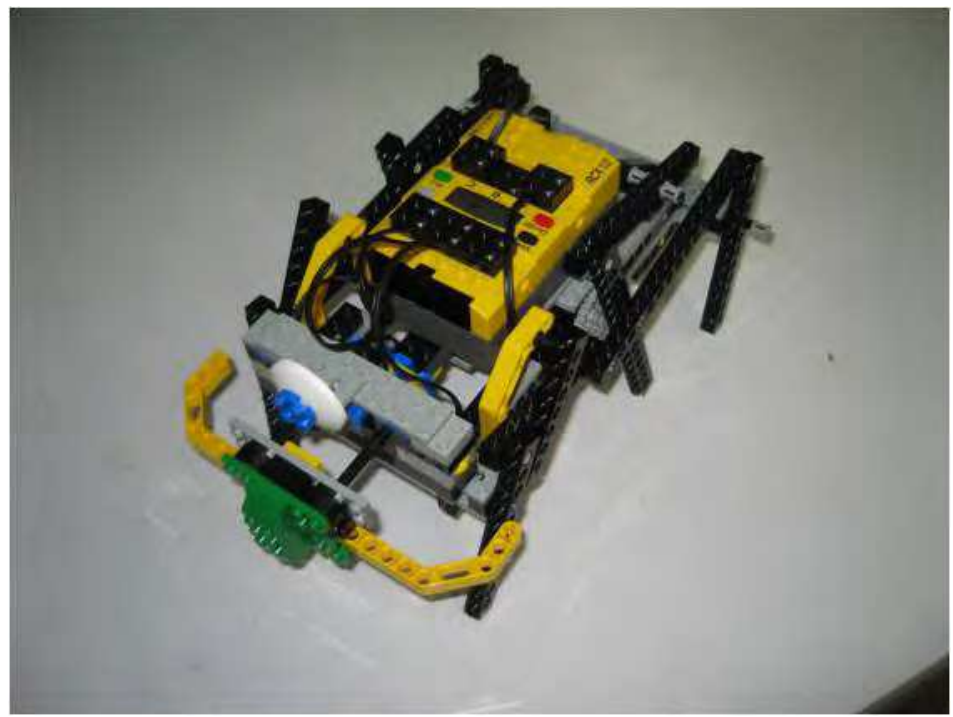

Fig. 5. Six legs autonomous robot, Musimusi No. 5

\subsection{Programming}

RCX is a delicate controller for MindStorms which has a 8 bit micro processor. It has three input ports and three output ports. Fig. 6 shows a RCX connecting with a motor, a lamp, a touch sensor, and a light sensor. A GUI based programming software, Robolab, is prepared as a regular programming software of MindStroms. Fig. 7 shows a programming environment of Robolab, where only users align command icons and connect them with wires in order to control some motors and actuators of MindStorms. All control command icon is prepared in the function panel. Operation commands for icons like wires can be selected on the tool panel as shown in Fig. 7. This programming environment of Robolab is well-suited to the beginners because of its friendliness, and makes it possible to code some high-level programming techniques such as conditional branching and infinite loop, etc.

Since this mechatronics course has to be implemented in short space of time, teachable programming techniques are restricted. Fortunately some fundamental programs are previously installed in software for self-education then there is no difficulties to introduce the basic function of Robolab and make students to understand a signal flow of program. After students understand and run the programs by using RCX, they try to make the programs working out several instructions in order to cultivate their programming ability. The following itemized instructions is an example of the training, and its corresponding program is shown in Fig. 7. 
I. When the touch sensor mounted at port 1 is pressed, then both of motors mounted at port $A$ and $C$ rotate in left direction for three seconds.

II. When the touch sensor mounted at port 1 is pressed again, both of motors mounted at port $\mathrm{A}$ and $\mathrm{C}$ rotate in right direction.

III. When the touch sensor mounted at port 1 is pressed, then the rotating two motors stop.

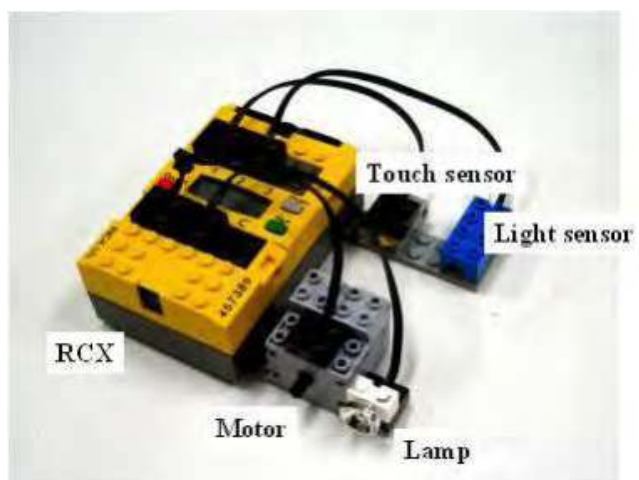

Fig. 6. A configuration of RCX, which connects with actuators and sensors.

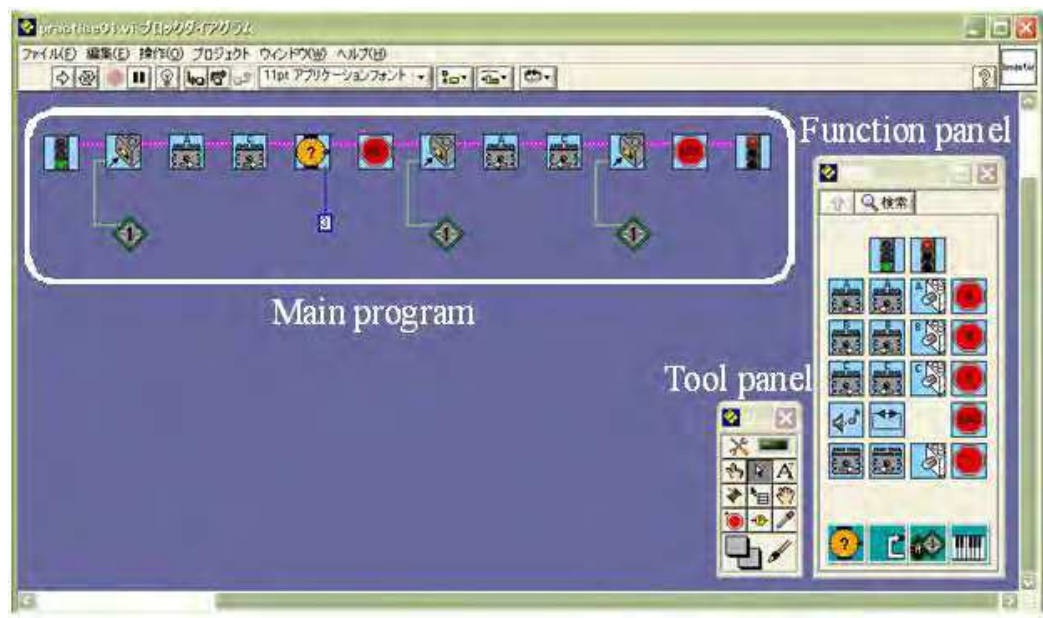

Fig. 7. Graphical user interface of Robolab

\subsection{Obstacle course}

Through the fourth and fifth sessions, students experienced a basic method to assemble a movable robot and learned how to code a program of ROBOLAB which controls the sensors and motors. A research factor of robot engineering is involved in the final session, where students try to make a mobile robot getting up to the goal with avoiding and/or overriding some obstacles on the field.

Only the final session, students are divided into five teams, then each team consists of two or three students. This team formation aims to avoid the restriction due to a number of 
components of MindStorms, and to make up for each other's deficiencies. A problem field is informed to student after the fifth session, and then students begin to think a strategy where they proposed shape and mechanism of robot and program code are proposed with each other within one week. In the final session students can use total 150 minutes for assembling and coding their robot and program, and the remaining time is used for competition. Of course there is no problem to exchange of opinions with other teams, and change their strategy they thought. Before the competition, they explain their strategy and the function of the developed robot.

The teams of the first group challenge a field of obstacle course shown in Fig. 8(a), where two obstacles are fixed between the start area and the goal area. A robot has to recognize the obstacles by using using touch sensors and change the direction of movement to avoid the obstacles.

Fig. 8(b) shows the second group's field of obstacle course, where an object which is twenty centimetres square by ten centimetres height is fixed in the centre of the field. A robot has to have functions that enables the robot to go strait and go around the obstacle in light direction. Only two rules a robot has to follow are that a robot must not contact the obstacle and take over the outer square line.

The third group's students try to make a robot that is able to go up the stairs. Fig. 8(c) shows a scheme of the field of obstacle course. The height of each step is five centimetres and and the width is fifteen centimetres. This stair-like obstacle is fixed at one meter distance from the start line, so the robot has to not only go straight and climb the stairs.

In the fourth problem three hurdles made of rubber grips are used as the obstacles. Fig. 8(d) shows a scheme of the fourth field of obstacle course. The hurdles are assigned fifteen centimetres apart and these height are one, two, and three centimetres from the floor. Additionally, hurdle's stiffness escalates afterward.

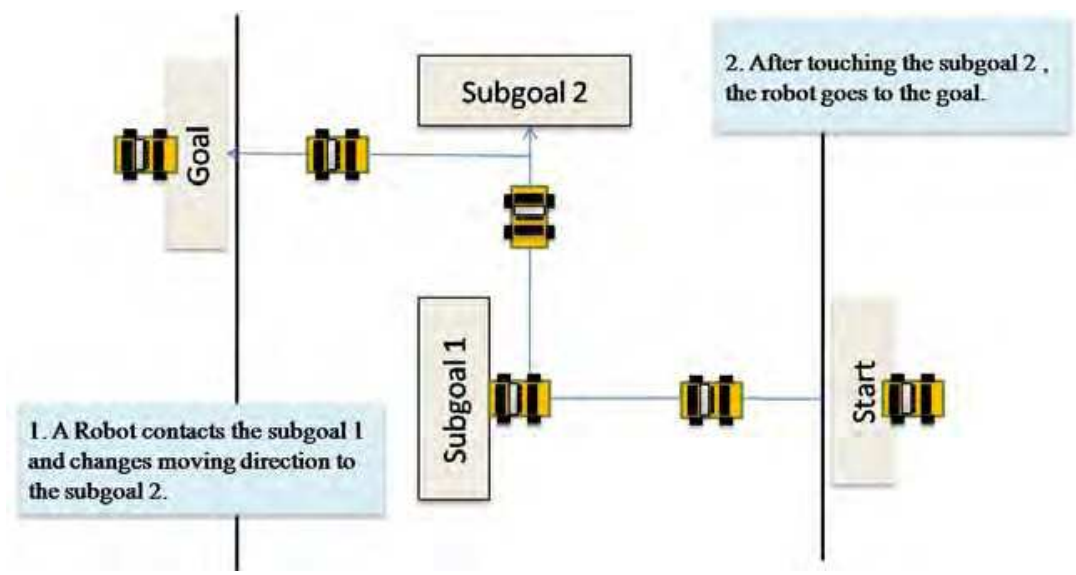

Fig. 8.(a) Scheme of the first obstacle course 


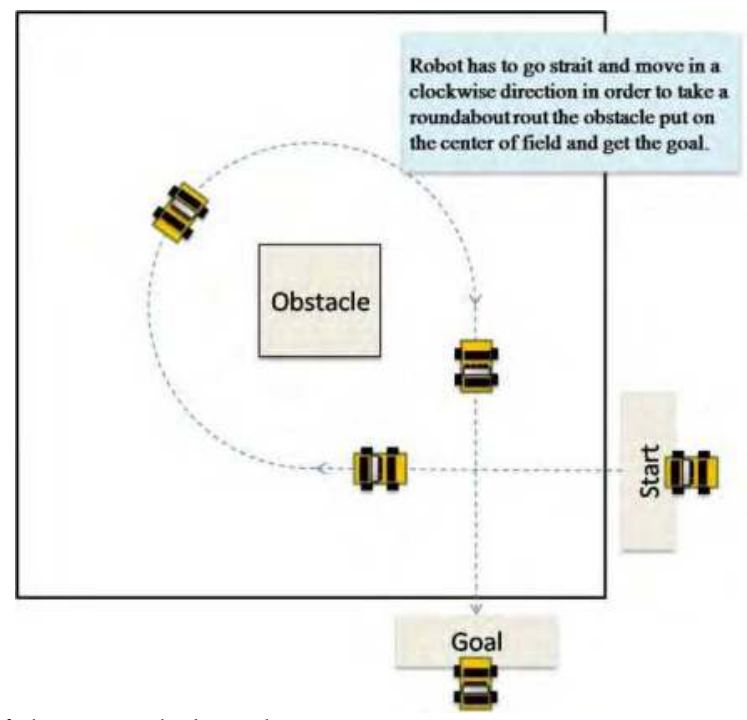

Fig. 8.(b) Scheme of the second obstacle course

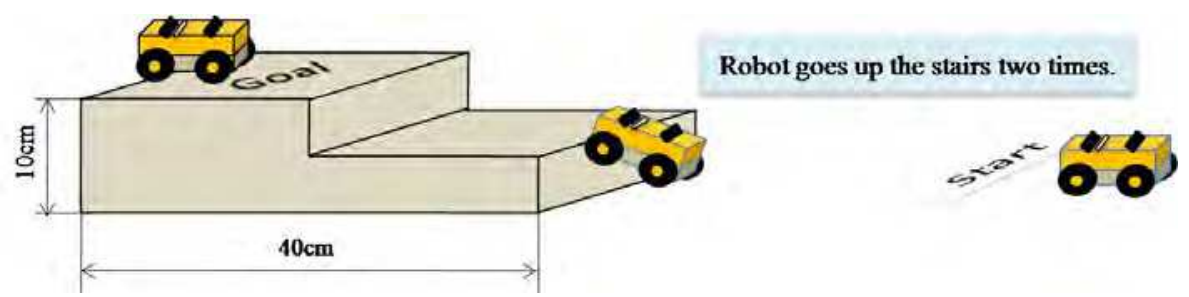

Fig. 8.(c) Scheme of the third obstacle course

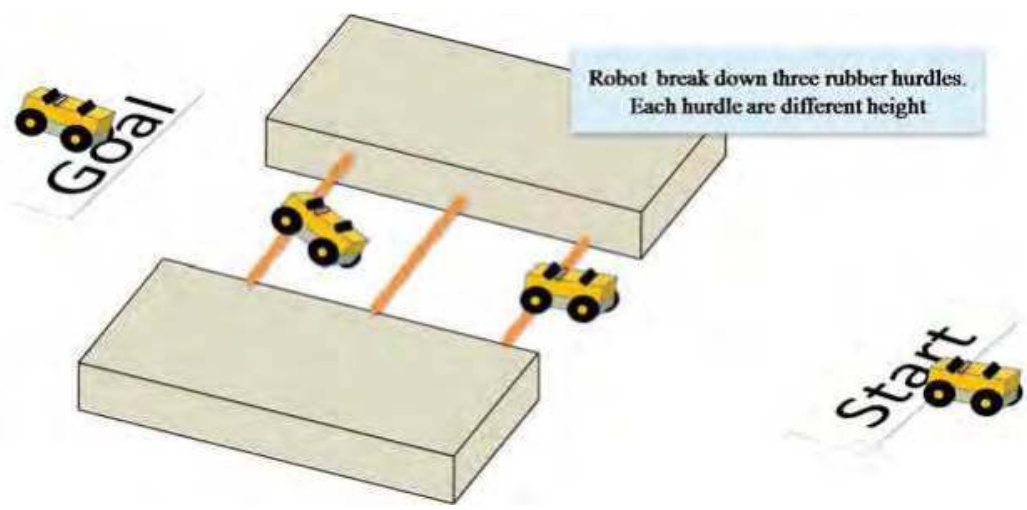

Fig. 8.(d) Scheme of the fourth obstacle course 


\section{Result}

This mechatronics installation course aims to make students to briefly know not only basic concepts of mechatronics but also difficulties of manufacturing. A toolkit of Mindstorms has an infinite of design freedom, so that this toolkit is able to foster students' creativity and design talent. Most of students had worked at this mechatronics installation course in earnest and developed interests in mechatronics. After learning basic techniques to assemble a movable robot and write a programming code, students addressed the challenge of obstacle course at the final session.

Fig. 9 shows two robots that could accomplish to clear the first obstacle course as shown in Fig. 8 (a). One is a type of autonomous robot that mounts RCX on its body and employed a rear-wheel-drive system. Students assumed that the functions required for a robot are to recognize accurately the surface of obstacle's wall, to keep going straight, and to change the direction of movement orthogonally. Firstly the robot moves toward the obstacle 1. After recognizing the surface of obstacle 1 by using the touch sensor fixed in front of body, the robot once goes back to turn a right and goes forward to the obstacle 2. After that, the robot goes to the goal in the same matter used to avoidance the obstacle 1.

On the contrary the robot shown in Fig. 9 (b) is manually controlled by the students. They used a RCX as a manual controller so that no sensors are mounted on the robot. The direction of movement is changed by differently adjusting the motor powers. The control signal is transmitted to the motor according to the timing of the student pushes a touch sensor mounted on RCX.

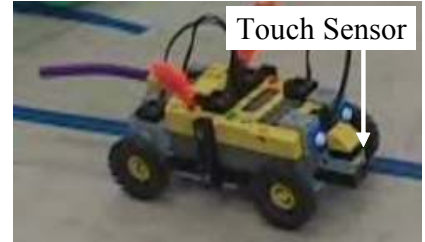

(a) Autonomous robot

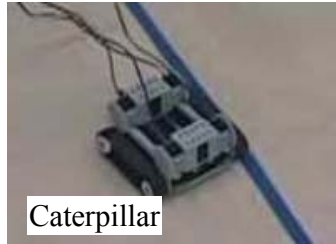

(b) Manual control robot

Fig. 9. Robots for the first obstacle avoidance problems

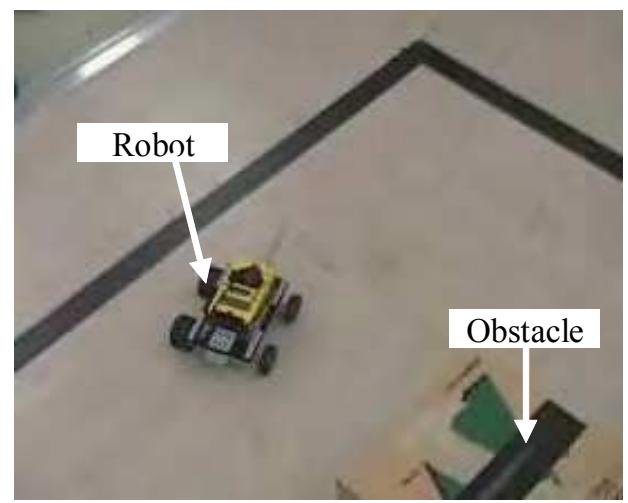

Fig. 10. An experimental scene of the second obstacle course 
Fig. 10 shows a scene of the competition of the second team. Unexpectedly only one robot shown in Fig. 10 could clear this obstacle course. Most of robot could not take a roundabout route within the outer square line. The team employed a four wheel drive system, however different sized wheels used in left and right sides in order to reduce turning radius of the robot. This team spent most of time to adjust their program of RCX by repeating test run, because rotational speeds of left and right motors have to be asymmetrically controlled even to keep going straight.

Five teams addressed the third problem shown in Fig. 8 (c). Most of teams aimed to climb the stairs by driving front wheels as shown in Fig. 11(a), however, no team could climb even the first step by using this way, they ended in failure due to the weight of RCX. Only one robot could complete the stair-like obstacle course. Fig. 11(b) shows an overview of the robot and describes its body's degrees of freedoms, where the lack gear moves along the joint q1 in order to lift up the front caterpillar. The q2 shows the angle of gradient for the front caterpillar. A remote control system is adopted in order to trim the weight of robot.

Along the following five steps, shown in Fig. 9(c), the robot climbed up stairs in the experiment; (1) the robot moves toward the stairs with fixing the angle of front caterpillar and quit going forward in front of the stairs. (2) Using the movable joints q1 and q2, the robot puts a part of front caterpillar on the first step. (3) The robot got back to the beginning posture as well as (1) on the first step. (4) The robot repeated the previous three behaviours once more to get the top of the stairs. (5) The robot arrived at the goal at last.

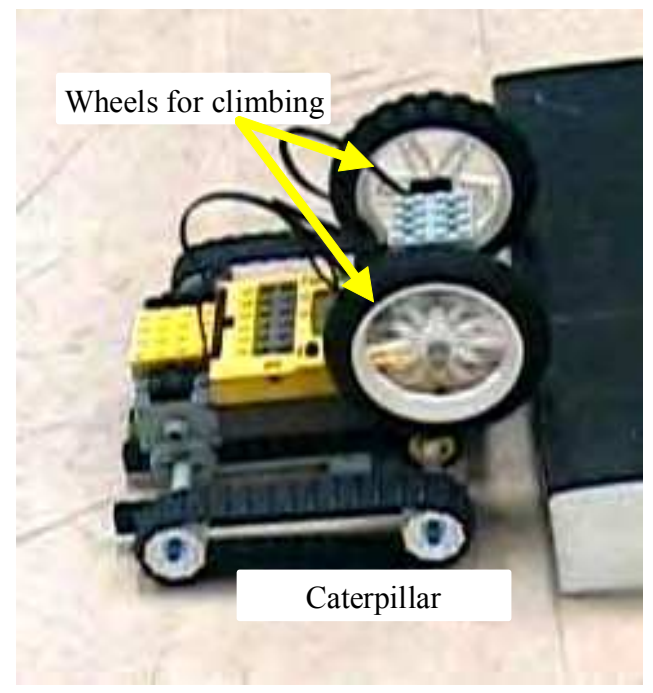

Fig 11.(a) An example of robot ended in failure for the third obstacle course 


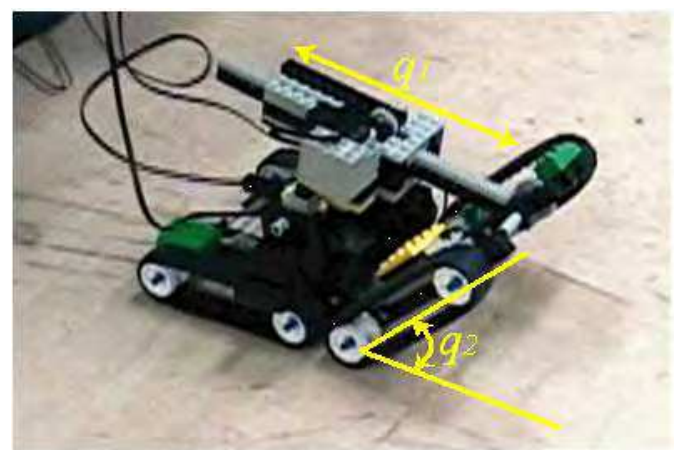

Fig. 11.(b) An overview of the robot completed the third obstacle course
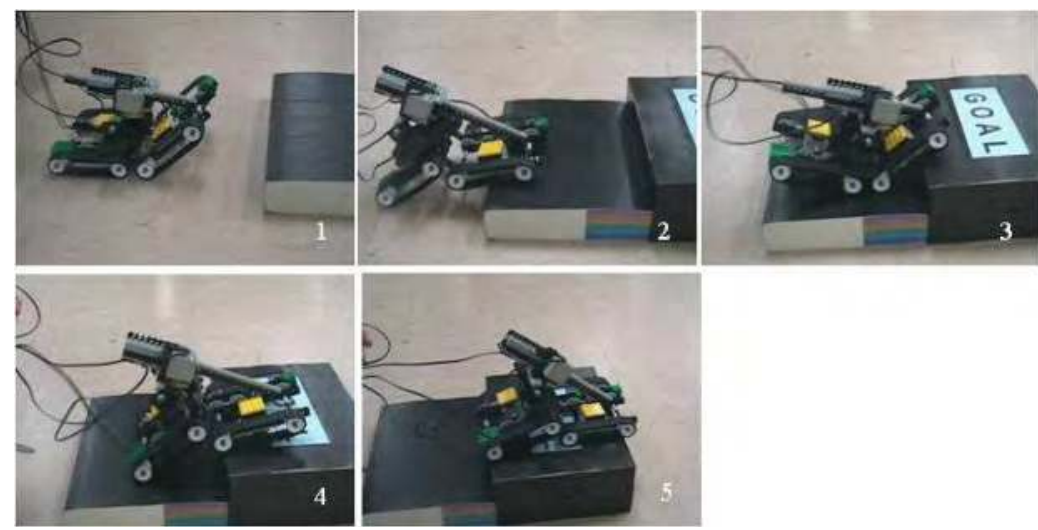

Fig. 11.(c) Experimental scenes going up the stairs in the third obstacle course



Fig. 12.(a) A tank type robot with double arms for the forth obstacle course 


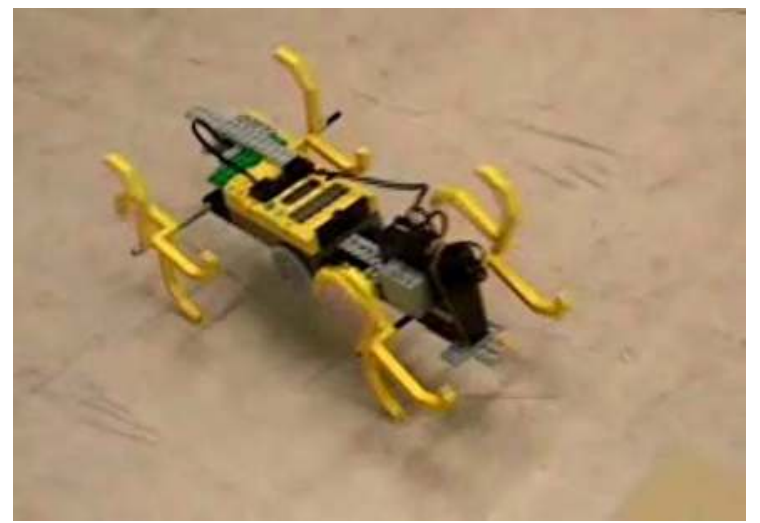

Fig. 12.(b) A long leg type robot for the forth obstacle course

Fig. 12 shows the robots could clear the forth obstacle course shown in Fig. 8(d). The robot shown in Fig. 12(a) rotates the front arm along the direction of q1 for the three purposes of the followings; (a) lifting the body up, (b) breaking down the rubber hurdles, and (c) going forward. The tires equipped at the end of arms does not rotate to go forward. As the result, this robot became entangled with rubbers several times, however, it finally could ride over all hurdles.

The robot, as shown in Fig. 12(b), only goes straight by rotating swastika shaped legs. These legs always lift the body higher than the rubber hurdles and enabled the robot to get the goal without the legs hitch the rubber hurdles.

According to the result of questionnaire about this mechatronics course, the following answers are received; all students had the interests in mechatronics, $68 \%$ of students were highly interested in the obstacle course conducted in the final session, and $17 \%$ of students were especially concerned with RCX programming. The others concerned with making the mechanical modules by using MindStorms, the miniature automation line system, and the assembling a multi-legged robot at the same rate.

\section{Discussion and Conclusion}

The author constructed an installation course of mechatronics and conducted on the students of department of mechanical engineering, Oita national college of technology. The course is composed of six sessions and is aiming to grow up the mechanical engineers who can adapt quickly to changes in industrial society. Then, the education programs of computer technology and information processing are more emphasized in this course. Certainly the specific subjects involved with mechatronics are constructed as a part of curriculum in the older grades, however there is some difficulties to make students of department of mechanical engineering to have interests in electronics and/or information science. Viewed in this light, it is better to begin mechatronics education with undergoing experiments like this course since they were in early grade.

This course employed the obstacle course as the final project. Working at making a robot for obstacle environment provides a research factor for students. They have an opportunity to 
discuss about their strategy to make a robot and they can experience concurrent engineering between assembly of robot and design of the controller. Meanwhile, development of a line tracing robot based on MindStorms has commonly used as a training issue in mechatronics education. A line tracing robot generally consists of mechanisms, light sensors, and motors. Additionally, a repeatable structure program is necessary. Most of mechatronics factors are contained in making a line tracing robot, however, there are lots of information about line tracing robot based on MindStorms and Robolab on the Internet. Certainly, difficulties of line tracing robot can be increased by changing the line width and/or the path of line. The reason why obstacle course is employed as the final project of the mechatronics course is that nobody knows an appropriate solution corresponding to obstacle environments.

Students worked in a team to address each given environment. Obstacle environment had to be different corresponding to students' growth through the year, so that the evaluation method for students' grade must not focus on the result of the final problem. In this course the grade of student is evaluated from their submitted reports for every session, where their activeness and written description of their impressions for each sessions become mainly evaluation object.

It was difficult to keep enough time to make students to learn programming techniques of Robolab such as branch connection and conditional statement, so that some students could not know convenience of programming for controlling actuators. Increment of the programming session make it possible to enhance the quality of robot and raise success rate of the final project. Temporal distribution of every kind of mechatronics contents is the most important problem.

\section{References}

Jin SATO. (2000). TETSUJIN Technique for MindStorms of Jin Sato, Ohmsha, ISBN 4-274-086828, Japan.

Jiro Eto, Yuki SHIRAKAWA, Tetsuro MAKISE, Jin SATO, Daisuke Kurabayashi, and Go FURUKAWA. (1999). LEGO MINDSTORMS Perfect guide, Shueisha, ISBN 978-488135-769-9, Japan.

Chieko KOMATSU, Toshikazu MINOSHIMA, and Takafumi MATSUMARU. (2000). Effeciency of experimental study on Mechatronics by using the LEGO MindStorm, Proceedings of Robotics and Mechatronics, Kumamoato prefecture, Japan, May and 2000, 1A1-81-128, (In Japanese).

Tomoyuki NAKASHIMA, Hiyoshi HAGIWARA, and Takafunmi MATSUMARU. (2001). Learning by Experience System on Mechatronics using LEGO MindStorms, Proceedings of Robotics and Mechatronics 2A1-A2, Kagawa prefecture, Japan, June and 2001

Eiichi INAGAKI, Yoshiaki SAWA, and Hiroyuki Okamura. (2001). Practical Education by using LEGO MindStorms at a Lecture Room, Proceedings of Robotics and Mechatronics 2P1-A2, Kagawa prefecture, Japan, June and 2001 


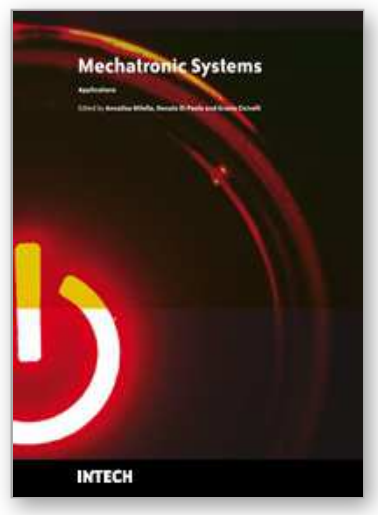

\author{
Mechatronic Systems Applications \\ Edited by Annalisa Milella Donato Di Paola and Grazia Cicirelli
}

ISBN 978-953-307-040-7

Hard cover, 352 pages

Publisher InTech

Published online 01, March, 2010

Published in print edition March, 2010

Mechatronics, the synergistic blend of mechanics, electronics, and computer science, has evolved over the past twenty five years, leading to a novel stage of engineering design. By integrating the best design practices with the most advanced technologies, mechatronics aims at realizing high-quality products, guaranteeing at the same time a substantial reduction of time and costs of manufacturing. Mechatronic systems are manifold and range from machine components, motion generators, and power producing machines to more complex devices, such as robotic systems and transportation vehicles. With its twenty chapters, which collect contributions from many researchers worldwide, this book provides an excellent survey of recent work in the field of mechatronics with applications in various fields, like robotics, medical and assistive technology, humanmachine interaction, unmanned vehicles, manufacturing, and education. We would like to thank all the authors who have invested a great deal of time to write such interesting chapters, which we are sure will be valuable to the readers. Chapters 1 to 6 deal with applications of mechatronics for the development of robotic systems. Medical and assistive technologies and human-machine interaction systems are the topic of chapters 7 to 13.Chapters 14 and 15 concern mechatronic systems for autonomous vehicles. Chapters 16-19 deal with mechatronics in manufacturing contexts. Chapter 20 concludes the book, describing a method for the installation of mechatronics education in schools.

\title{
How to reference
}

In order to correctly reference this scholarly work, feel free to copy and paste the following:

Tatsushi Tokuyasu (2010). Installation of Mechatronics Education Using the MindStorms for Dept. of Mechanical Engineering, O.N.C.T, Mechatronic Systems Applications, Annalisa Milella Donato Di Paola and Grazia Cicirelli (Ed.), ISBN: 978-953-307-040-7, InTech, Available from:

http://www.intechopen.com/books/mechatronic-systems-applications/installation-of-mechatronics-_educationusing-the-mindstorms-for-dept-of-mechanical-engineering-o-n-

\section{INTECH}

open science | open minds

\section{InTech Europe}

University Campus STeP Ri

Slavka Krautzeka 83/A

51000 Rijeka, Croatia

Phone: +385 (51) 770447

\section{InTech China}

Unit 405, Office Block, Hotel Equatorial Shanghai

No.65, Yan An Road (West), Shanghai, 200040, China

中国上海市延安西路65号上海国际贵都大饭店办公楼 405 单元

Phone: +86-21-62489820 
Fax: +385 (51) 686166

Fax: +86-21-62489821

www.intechopen.com 
(C) 2010 The Author(s). Licensee IntechOpen. This chapter is distributed under the terms of the Creative Commons Attribution-NonCommercialShareAlike-3.0 License, which permits use, distribution and reproduction for non-commercial purposes, provided the original is properly cited and derivative works building on this content are distributed under the same license. 